Research Paper:

\title{
The Elders' Spiritual Well-Being and Their Quality of Life: A Cross-Sectional Study
}

Hasan Jafaripoor ${ }^{1}$ (1), Mehdi Safarabadi² (1), Yasaman Pourandish ${ }^{3}$ (), Ali Khanmohammadi ${ }^{3}$ (1), Seied Mohammad Aghaiepoor $^{3}$ (1), Amir Rahbarian $^{3}$ (1), Hossein Poorcheraghi ${ }^{3}$ (1), Ali Jadidi ${ }^{4,5^{*}}$ (1)

1. Department of Islamic Sciences, Faculty of Medical Sciences, Arak University of Medical Sciences, Arak, Iran 2. Department of Nursing, Faculty of Nursing and Midwifery, Iran University of Medical Sciences, Tehran, Iran. 3. Department of Nursing, Student Research Committee, Arak University of Medical Sciences, Arak, Iran. 4. Chronic Diseases (Home Care) Research Center, Hamadan University of Medical Sciences, Hamadan, Iran 5. Department of Nursing, Faculty of Nursing and Midwifery, Arak University of Medical Sciences, Arak, Iran.

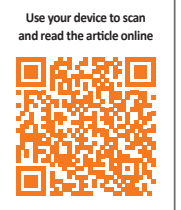

ciftation Jafaripoor, H., et al., 2018. The Elders' Spiritual Well-Being and Their Quality of Life: A Cross-Sectional Study. Journal of Client-Centered Nursing Care, 4(3), pp. 145-154. https://doi.org/10.32598/jccnc.4.3.145

oil https://doi.org/10.32598/jcenc.4.3.145

\section{(c) (1) (\$)}

Article info:

Received: 13 Dec 2017

First Revision: 15 Jan 2018

Accepted: 26 Apr 2018

Published: 01 Aug 2018

Keywords:

Elderly, Quality of Life (QoL), Spiritual WellBeing (SWB)

\begin{abstract}
A B S T RA C T
Background: Because of the rising number of elderly people, their Quality of Life have become more important. Health status has been considered as one of the factors that affect life quality and Spiritual Well-Being is one of its important dimensions. The present study aimed to determine the relationship between Spiritual Well-Being and Quality of Life among the elderly people residing in Arak City, Iran.
\end{abstract}

Methods: This is a cross-sectional and correlational study. The study sample comprised 400 elderly people residing in Arak, Iran who were selected by cluster sampling method. Spiritual WellBeing was measured using Spiritual Well-Being scale (SWB) and the Quality of Life was assessed by Older People's Quality of Life Questionnaire (OPQOL-35). The obtained data were analyzed by descriptive statistics, along with Pearson correlation test, t-test, and ANOVA in SPSS V. 16.

Results: The Mean \pm SD score of life quality among the elderlies was $76.24 \pm 17.84$ and was associated with their marital status and education level $(\mathrm{P}=0.001)$. The Spiritual Well-Being score of most elderly people ranged from moderate to high and the Mean $\pm \mathrm{SD}$ score of their Spiritual Well-Being was $96.47 \pm 13.43$. There was a significant relationship between Spiritual Well-Being and the Quality of Life ( $\mathrm{r}=0.37, \mathrm{P}=0.0001)$

Conclusion: According to the findings, more attention should be paid to the factors related to the Quality of Life for taking care of the elderly people. Considering the relationship between Spiritual Well-Being and Quality of Life among these elderlies, provision of spiritual care for this group of society is recommended.

\footnotetext{
* Corresponding Author:

Ali Jadidi, PhD.

Address: Chronic Diseases (Home Care) Research Center, Hamadan University of Medical Sciences, Hamadan, Iran.

Tel: +98 (935) 7135041

E-mail:jadidiali83@yahoo.com
} 


\section{Highlights}

- Married elderly people reported a higher quality of life than others.

- Spiritual performance is not related to loss in physical ability.

- All dimensions of quality of life among Iranian elderly men were significantly higher than those in older Iranian women.

- There is a correlation between spiritual well-being and quality of life.

\section{Plain Language Summary}

The number of elderly people is increasing all over the world and it is important to know about their quality of life. One of the important areas affecting on quality of life is spiritual health state that we aimed to clarify their relationship. A group of elderly people living in one of the Iranian cities, Arak, were asked to fill the questionnaire related to their health state. After analyzing the gathered data, we realized the strong relationship between spiritual well-being and how these people find life enjoyable and being satisfied.

\section{Background}

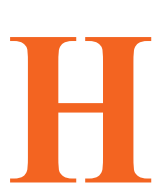

ealth improvement, preventive care development, and controlling communicable diseases have increased life span and the population of the elderlies. Aging phenomenon is also the consequence of social and economic conditions, reduction of mortality and morbidity, as well as an increase in life expectancy in the developed countries. However, this is also true for developing countries. It is anticipated that by 2020, the number of world's older population will reach a billion. In general, $16 \%$ of the population in the industrialized countries are elderly people, and it is expected to increase up to $3 \%$ over the next few decades (Chand \& Tung 2014). According to 2011 Iran Statistical Center report, the number of elderly people over 60 years old was about 6.2 million, about $8.2 \%$ of the population of Iran (Mehri Nejad, Ramezan Saatchi \& Paydar 2017). Obviously, the elderly population of Iran will increase in the future (Zeinalhajlu, Amini \& Tabrizi 2015).

Some factors such as the increasing number of elderly people suffering from disabilities and functional disorders, lack of a supportive system in the families due to shrinking family size, women's employment, and family members' dispersion will increase the request for longterm care for the elderly in future decades (López-Soto 2015). "Increasing the life expectancy" was regarded as the main challenge of general health in the $20^{\text {th }}$ century, which has changed into "life with better quality" in the $21^{\text {st }}$ century. The main objective of life in old age is not only living longer, but also how to live; therefore, their lifestyle and life quality should be taken into consideration and the familiarity with the factors affecting their life quality can contribute to the quality of the elderlies' life (Birren et al. 2014).

Along with old age, cognitive compatibility and selfreliance may decrease which in turn influences the life quality of the elderlies (Zeinalhajlu, Amini \& Tabrizi 2015). Generally, aging is a predisposing factor to some diseases and disabilities. Furthermore, negative effects of ageing on the ability to protect independence will call for assistance (Kiosses \& Alexopoulos 2014). These problems and difficulties, which occur physiologically during the old age, can influence the reduction of life quality during the elderly period. In Iran, about $28 \%$ of the elderly people have limitations in physical activities and need help to do their daily activities that leads to poor Quality of Life (Awick et al. 2015).

A study conducted on elderly people residing in Tehran City demonstrated a high rate of disability among this population (Rashedi et al. 2016). Given that the life quality can be easily threatened in this period, consideration of contextual factors influencing the life quality of elderlies can play a significant role in enhancing their Quality of Life (Awick et al. 2015). Based on some evidence, lifestyle can influence physical aging (Kim et al. 2015). Meanwhile, some studies have indicated that the risk of physical and mental diseases among elderly people who live alone was higher than those living with their family members (Liang \& Lu 2014). 
Health status as an important factor can affect Quality of Life, especially among the elderlies. Based on the World Health Organization definition, health has physical, mental, social, and spiritual dimensions. It is believed that spiritual dimension of health should be greatly emphasized. Some studies revealed that without Spiritual Well-Being, other mental, social, and physical dimensions will not function properly or reach their maximum capacity. Therefore, the highest level of life quality will not be achieved (Chatterji et al. 2015). Recently, a relationship has been found between religion, spirituality, and health status. Some studies have reported that spirituality plays a significant role in one's health, because religion and spirituality are considered as two important sources for adaptation with stressful events of life (Anand, Jones \& Gill 2015).

The results of the studies conducted on Spiritual WellBeing among the patients suffering from cancer have revealed a direct relationship between the patients' age and their Spiritual Well-Being, as $96 \%$ of the patients over 70 years had high Spiritual Well-Being. Recently, some studies have suggested spiritual forces as a significant factor which provides equanimity, strength, and indescribable vitality for elderly people. It has attracted a lot of attention among nursing theorists, too (Jadidi et al. 2011).

The elderly people with stronger religious beliefs enjoy a better health status compared to others. Furthermore, it has been found that faithful elderlies who suffer from a physical disease have better performance and receive better results from their treatments, compared to those with weak faith (Kim, Kim-Godwin \& Koenig 2016). Some other studies have found a significant relationship among spirituality, religiosity, and mental health of elderly people over the age of 60 (Zimmer et al. 2016). Therefore, given the importance of Quality of Life among the elderlies, the present study was conducted to determine the relationship between Spiritual Well-Being and Quality of Life among elderly people living in Arak City, Iran.

\section{Materials and Methods}

This was a cross-sectional, correlational study which was conducted on 400 elderly people over 60 years living in Arak, a city in the center of Iran. The study data were collected through cluster sampling method. For this purpose, researchers divided the city into four areas using the city map and Arak municipality quadricdistrict division. So the research could cover the whole city. Then, the researchers marked crowded places in each area like malls, parks, bus stops, and mosques and filled the questionnaires by interviewing citizens older than 60 , considering at least 95 subjects from each area. The inclusion criteria comprised having no chronic disability, physical and mental illness, lacking cognitive disorders and being literate or able to interview. Since most of the subjects were illiterate, the researchers filled in most questionnaires by interview. The sampling lasted for three months (December 2016, January and February 2017).

The obtained data were collected by the Older People's Quality of Life Questionnaire (OPQOL-35) and Spiritual Well-Being Scale (SWB). OPQOL-35 has been designed by Bowling and Stenner and its psychometric properties were evaluated in 2011. The reliability and validity of this questionnaire and its Persian version was confirmed in some studies (Jokinen, 2014; Nikkhah et al. 2017). The questionnaire is a 5-point Likert-type scale that rates Quality of Life from (Strongly agree) to (Strongly disagree) and consists of 35 items of religion/culture (2 items), health (4 items); overall life (4 items); area: home and neighborhood (4 items); financial status (4 items); psychological and emotional wellbeing (4 items); freedom, independence, control over life (5 items); and social relationships and participation (8 items). Higher scores indicate higher QoL. The total scale ranges from 35 (QoL could not be worse) to 175 (QoL could not be better) (Bowling 2009).

Spiritual Well-Being was measured by SWB which is designed by Paluotzian and Ellison and consists of 20 questions, which is answered based on a 6-point Likerttype scale from "completely disagree" to "completely agree". The scale has been divided into two subscales of religious and existential well-being, each including 10 questions, and the total score ranges from 10 to 60 . Religious well-being is shown by individual phrases and existential well-being by coupled phrases. The total score is the sum of the two subscales and ranged from 20 to 120. In sum, the scores are classified into three categories: low Spiritual Well-Being (20-40), moderate Spiritual Well-Being (41-99) and high Spiritual Well-Being (100-120) (Chen et al. 2017).

Poloutzian and Ellison calculated its Cronbach $\alpha$ coefficients as 0.91 , and 0.93 for religious well-being and existential well-being, respectively. In addition, Allahbakhshian et al. (2010) obtained the Cronbach $\alpha$ coefficient of 0.82 for the questionnaire after translating the questionnaire into Persian, and they also confirmed its validity. The collected data were analyzed by descriptive statistics of frequency, mean and standard deviation, and inferential statistics of Pearson correlation coefficient, t-test and ANOVA in SPSS V. 16. 
Table 1. Demographic characteristics of the study elderlies

\begin{tabular}{|c|c|c|}
\hline & Variable Type & Demographic Characteristics \\
\hline & Age, $y$ & $68.94 \pm 7.59$ \\
\hline \multirow{2}{*}{ Sex } & Male & $61(244)$ \\
\hline & Female & 39 (156) \\
\hline \multirow{4}{*}{ Marital status } & Single & $9.5(38)$ \\
\hline & Married & $69.45(278)$ \\
\hline & Divorced & $3.8(15)$ \\
\hline & Widow/widower & $17.2(69)$ \\
\hline \multirow{4}{*}{ Level of education } & Illiterate & $29.2(117)$ \\
\hline & Elementary & $24(96)$ \\
\hline & Middle school and high school & $11.3(45)$ \\
\hline & Diploma and higher & $35.4(142)$ \\
\hline
\end{tabular}

Data are presented as Mean \pm SD or No. (\%)

was $96.47 \pm 13.43$. In other words, the Spiritual Well-Being of a majority of the subjects was at moderate (48.2\%)

\section{Results}

Table 1 presents the demographic characteristics of the study samples. The study results indicated that Mean \pm SD score of the elderly Quality of Life was $76.24 \pm 17.87$. Their mean score of Spiritual Well-Being or high $(50.4 \%)$ level. Although the female's mean score of Spiritual Well-Being was slightly greater than that of males, the difference was not statistically significant. Moreover, the mean score of religious well-being was greater than that of existential well-being (Table 2).

Table 2. Descriptive statistics of the research variables

\begin{tabular}{|c|c|c|c|}
\hline Variable & Mean \pm SD & Max & Min \\
\hline Spiritual well-being & $96.43 \pm 13.43$ & 120 & 20 \\
\hline Existential well-being & $47.29 \pm 7.9$ & 60 & 10 \\
\hline Religious well-being & $48.7 \pm 7.17$ & 60 & 10 \\
\hline Quality of life & $76.24 \pm 17.84$ & 160 & 48 \\
\hline Health & $10.22 \pm 2.27$ & 18 & 4 \\
\hline Social relations & $8.72 \pm 3.76$ & 25 & 5 \\
\hline Independence, control of life and freedom & $8.75 \pm 33.6$ & 20 & 4 \\
\hline Home and neighborhood & $65.5 \pm 7.2$ & 20 & 4 \\
\hline Mental and emotional health & $18.8 \pm 98.2$ & 19 & 4 \\
\hline Financial condition & $35.11 \pm 79.8$ & 16 & 4 \\
\hline Leisure time and activities & $22.12 \pm 98.3$ & 28 & 6 \\
\hline
\end{tabular}


Table 3. The correlation between different dimensions of Quality of Life and Spiritual Well-Being

\begin{tabular}{|c|c|c|c|}
\hline & \multirow{2}{*}{ Variable } & \multicolumn{2}{|c|}{ Pearson Correlation Test } \\
\hline & & $\mathbf{R}$ & $\mathbf{P}$ \\
\hline \multirow{3}{*}{ Quality of Life } & Existential well-being & 0.326 & 0.000 \\
\hline & Religious well-being & 0.587 & 0.000 \\
\hline & Spiritual well-being & 0.456 & 0.000 \\
\hline \multirow{8}{*}{$\begin{array}{c}\text { Spiritual } \\
\text { well-being }\end{array}$} & Health & 0.65 & 0.022 \\
\hline & Social relations & 0.022 & 0.964 \\
\hline & Independence, control of life and freedom & 0.135 & 0.007 \\
\hline & Home and neighborhood & 0.36 & 0.000 \\
\hline & Mental and emotional health & 0.043 & 0.000 \\
\hline & Financial condition & 0.087 & 0.081 \\
\hline & Leisure time and activities & 0.32 & 0.000 \\
\hline & Quality of Life & 0.37 & 0.000 \\
\hline
\end{tabular}

Client- Centered Nursing Care

The participant's Spiritual Well-Being score was not related to any demographic variables $(\mathrm{P}=0.08)$. Similarly, the scores of existential and religious well-being had no relationship with any demographic variables $(\mathrm{P}=0.06)$. As shown in Table 3, the Pearson correlational coefficient test demonstrated that Spiritual Well-Being of the elderly people was related to their life quality $(\mathrm{r}=0.456$; $\mathrm{P}=0.0001$ ).

Based on $t$ test results, the Quality of Life score was not related to the gender of the subjects. Furthermore, the results of the ANOVA indicated that the Quality of Life score was associated with marital status and education level $(\mathrm{P}=0.009)$, as the widows with lower education level got less score than others. However, the Quality of Life score had no relationship with other demographic variables $(\mathrm{P}=0.12)$.

\section{Discussion}

Since the baseline indicator and normative criterion of the Quality of Life among the elderly have not been already determined in Iran, we can assume the mean of $50 \%$ with a standard deviation of $10 \%$ as the norm of the community and an acceptable indicator for the Quality of Life among the elderlies considering 0-100 criteria which are relevant to the present questionnaire (Jadidi et al. 2011). Therefore, the Quality of Life of the elderly was moderate in the present study, which is consistent with the results of some other studies.

Kumar \& Majumdar (2014), Yin et al. (2017), and Hongthong \& Somrongthong (2015) determined the life quality among the elderlies as moderate in India, Malaysia, and Thailand, respectively. However, some other studies have shown that the Quality of Life among elderly people in Iran is not desirable (Mazloomymahmoodabad et al. 2014; Nazemi et al. 2015; Jahromi, Ramezanli \& Taheri 2015).

In this study, the results of $t$ test indicated that the Quality of Life score was not related to the gender. This finding was congruent with some other studies (Steptoe, Deaton \& Stone 2015; Ebrahimi et al. 2014). However, the total mean score of life quality among Iranian male elderlies was significantly higher than that of woman in all dimensions (Hajian-Tilaki, Heidari \& Hajian-Tilaki 2017). In addition, some studies have reported that the male subjects have obtained higher Quality of Life scores compared to their female counterparts (Khaje-Bishak et al. 2014). A study in Saudi Arabia indicated a significant difference between the total mean score of life quality among elderly men and women (Soliman et al. 2015). A study in Vietnam assessed the total life quality scores among the elderly men (75.32) and women (72.32) and reported that the life quality among the el- 
derly men in all dimensions was higher than that of the women (Van Nguyen et al. 2017).

Some studies have shown that the Quality of Life score among elderly women was lower than that of men at the same age and have related it to longer life span, more illnesses, lower educational level and income, lack of autonomy, and more social and cultural limitations imposed on women (Mangen et al. 2017). The mean score of life quality among the elderlies in Belo Horizonte City in Brazil and in Taiwan was 52.57 and 58.3, respectively (Miranda, Soares \& Silva 2016; Chen \& Chen 2017).

As the results of these two studies indicate, the mean score of Quality of Life among these elderlies is higher than that the score in the present study. It can be related to the cultural differences, type of disease, and socioeconomic status of the subjects. Moreover, the results of the present study indicated no relationship between the mean score of Quality of Life and other variables, except for marital status; as the married elderlies reported higher Quality of Life than others $(\mathrm{P}=0.009)$ which is consistent with the results of some studies (Jadidi et al. 2011; Hajian-Tilaki, Heidari \& Hajian-Tilaki 2017; Shi et al. 2017; Wang et al. 2017b; Zhou \& Hearst 2016). However the results were inconsistent with some other studies (Buhse, Banker \& Clement 2014). In addition, some studies indicate that elderly people with higher educational level have better health status (Chen, Feng \& Li 2014; Dai et al. 2016; Tkatch et al. 2016).

The Mean \pm SD score of Spiritual Well-Being of the elderly in the present study was high $(96.47 \pm 13.43)$ and more than half of the subjects achieved a high Spiritual Well-Being score which is in line with many studies (Anand, Jones \& Gill 2015; Adib-Hajbaghery \& Faraji 2015; Alihosseini, Najar \& Haghighizadeh 2017; Chaves $\&$ Gil 2015). Some studies have concluded that religion and spirituality are important sources of strength and support among elderly people, which help them to tolerate critical and stressful situations (Jadidi et al. 2011). Although physical abilities decline with aging, spiritual function does not necessarily weaken (Nasiry, Bagheri \& Malekzadeh 2016).

In the current study, no significant difference was found between different dimensions of Spiritual WellBeing. However, the finding was inconsistent with the results of other studies (Nasiry, Bagheri \& Malekzadeh 2016; Seraji, Shojaezade \& Rakhshani 2016). Some studies have indicated that Spiritual Well-Being is related to age, marital status, and educational level, i.e. those with deceased or divorced spouse and lower- education had lower Spiritual Well-Being scores than others (Anand, Jones \& Gill 2015; Poor et al. 2016; Ebrahimi et al. 2014). It was found that older people with stronger religious beliefs have a greater life expectancy than others (Poor et al. 2016). However, the present study, did not confirm these results.

The Pearson correlation test determined a significant relationship between Spiritual Well-Being and elderlies' Quality of Life ( $\mathrm{r}=0.445 ; \mathrm{P}=0.000)$. In fact, based on this finding, the Quality of Life and Spiritual WellBeing assigned $20 \%$ of common variance to themselves. In other words, $20 \%$ of life quality changes are related to Spiritual Well-Being. This finding is in line with some other studies which emphasized that higher spirituality leads to better health status (Finocchiaro, Roth \& Connelly 2014; Fredriksen-Goldsen 2014; Ryff \& Singer 2008; Velasco-Gonzalez \& Rioux 2014; Wang, Chow \& Chan 2017a).

In fact, spirituality during loneliness and difficulties helps to relax and reduce anxiety, and induces a sense of meaningfulness, purposefulness, creativity, and cohesion (Lewis et al. 2014). According to Walker et al. (2017) optimism or a report of good health status, despite physical condition, is a possible way to explain the relationship between Spiritual Well-Being and Quality of Life, as elderly people with higher level of Spiritual Well-Being may be more optimistic and have a better view of their health status.

Body, mind, and spirit are associated with each other; accordingly providing spiritual care is an essential part of holistic nursing care. In other words, health care providers should consider physical, psychological, sociocultural, and spiritual dimensions of health in their caring services (Farahaninia et al. 2018). Based on the results of the present study, spirituality and teaching the ways of Spiritual Well-Being promotion should be considered by those involved in providing care to elders. Along with meeting elders' spiritual needs, their Quality of Life can be improved.

On the other hand, a comprehensive care of patients, including spiritual care and attention to their mental and psychological problems should be prioritized as the main objective of nursing. Therefore, in order to improve the Quality of Life of patients, especially elderlies, it is necessary to pay attention to the spiritual dimension of their lives. Furthermore, the necessary conditions should be provided for nurses' participation in training courses, and conferences on the spiritual aspects of human existence and spiritual care to enhance their knowledge and 
skills in this field. Because of the descriptive correlational design of the study, the results should be generalized with caution.

\section{Ethical Considerations}

\section{Compliance with ethical guidelines}

After obtaining permission from the Ethics Committee of Arak University of Medical Sciences, the researchers completed the study questionnaires. All participants signed the informed consent before filling in the questionnaire and then the questionnaire was given to them along with providing the necessary explanations about the purpose of the study and confidentiality of the obtained data.

\section{Funding}

This research did not receive any specific grant from funding agencies in the public, commercial, or not-forprofit sectors.

\section{Authors contributions}

All authors contributed in preparing this article.

\section{Conflicts of interest}

The authors declared no conflict of interest.

\section{Acknowledgements}

The authors would like to appreciate the Research Deputy of Arak University of Medical Sciences.

\section{References}

Adib Hajbaghery, M. \& Faraji, M., 2015. Comparison of happiness and Spiritual Well-Being among the community dwelling elderly and those who lived in sanitariums. International Journal of Community Based Nursing and Midwifery, 3(3), pp. 216-26. [PMID] [PMCID]

Alihosseini, E., Najar, S. \& Haghighizadeh, M. H., 2017. The relationship between sleep disorders during pregnancy and miscarriage. Jundishapur Journal of Chronic Disease Care, 6(2), p. e41340

Allahbakhshian, M., et al., 2010. [A Survey on relationship between spiritual well being and Quality of Life in multiple sclerosis patients (Persian)]. Zahedan Journal of Research in Medical Sciences, 12(3), pp. 29-33.

Anand, V., Jones, J. \& Gill, P. S., 2015. The relationship between spirituality, health and life satisfaction of undergraduate stu- dents in the UK: An online questionnaire study. Journal of Re ligion and Health, 54(1), pp. 160-72. [DOI:10.1007/s10943-0139792-0] [PMID]

Awick, E. A., et al., 2015. Differential exercise effects on Quality of Life and health-related Quality of Life in older adults: A randomized controlled trial. Quality of Life Research, 24(2), pp. 455-62. [DOI:10.1007/s11136-014-0762-0] [PMID] [PMCID]

Birren, J. E., et al., 2014. The concept and measurement of Quality of Life in the frail elderly. Cambridge: Academic Press.

Bowling, A., 2009. The psychometric properties of the older people's Quality of Life questionnaire, compared with the CASP 19 and the WHOQOL-OLD. Current Gerontology and Geriatrics Research, 2009, p. 298950. [DOI:10.1155/2009/298950]

Buhse, M., Banker, W. M. \& Clement, L. M., 2014. Factors associated with health-related Quality of Life among older people with multiple sclerosis. International Journal of MS Care, 16(1) pp. 10-9. [DOI:10.7224/1537-2073.2012-046] [PMID] [PMCID]

Chand, M. \& Tung, R. L., 2014. The aging of the world's population and its effects on global business. Academy of Management Perspectives, 28(4), pp. 409-29. [DOI:10.5465/amp.2012.0070]

Chatterji, S., et al., 2015. Health, functioning, and disability in older adults-present status and future implications. The Lancet, 385(9967), pp. 563-75. [DOI:10.1016/S0140-6736(14)61462-8]

Chaves, L. J. \& Gil, C. A., 2015. Older people's concepts of spirituality, related to aging and Quality of Life. Ciencia $\mathcal{E}$ Saude Coletiva, 20(12), pp. 3641-52. [DOI:10.1590/1413812320152012.19062014] [PMID]

Chen, C. X., Feng, L. N. \& Li, S. X., 2014. The correlation between socioeconomic status and health self-management in the elderly. International Journal of Nursing Sciences, 1(1), pp. 410-5. [DOI:10.1016/j.ijnss.2014.10.008

Chen, H. M. \& Chen, C. M., 2017. Factors associated with Quality of Life among older adults with chronic disease in Taiwan. International Journal of Gerontology, 11(1), pp. 12-5. [DOI:10.1016/j.ijge.2016.07.002]

Chen, Y. H., et al., 2017. The relationship of physiopsychosocial factors and Spiritual Well-Being in elderly residents: Implications for evidence-based practice. Worldviews on Evidence-Based Nursing, 14(6), pp. 484-91. [DOI:10.1111/wvn.12243] [PMID]

Dai, Y., et al., 2016. Social support and the self-rated health of older people: A comparative study in Tainan Taiwan and Fuzhou Fujian province. Medicine, 95(24), P. e3881. [DOI:10.1097/ MD.0000000000003881]

Ebrahimi, H., et al., 2014. Relationship between Spiritual WellBeing and Quality of Life in hemodialysis patients. Journal of Nursing and Midwifery Sciences, 1(3), pp. 41-8. [DOI:10.18869/ acadpub.jnms.1.3.41]

Farahaninia, M., et al., 2018. Nurses' attitudes towards spiritual care and spiritual care practices. Journal of Client-Centered Nursing Care, 4(2), pp. 61-8. [DOI:10.32598/10.32598/jccnc.4.3.61]

Finocchiaro, D. N., Roth, P. A. \& Connelly, C. D., 2014. Spiritual Well-Being as predictor of Quality of Life for adults with paraplegia. Rehabilitation Nursing, 39(6), pp. 285-93. [DOI:10.1002/ rnj.161] [PMID]

Fredriksen-Goldsen, K. I., 2014. Successful aging among LGBT older adults: Physical and mental health-related Quality of Life 
by age group. Gerontologist, 55(1), pp. 154-68. [DOI:10.1093/ geront/gnu081] [PMID] [PMCID]

Hajian-Tilaki, K., Heidari, B. \& Hajian-Tilaki, A., 2017. Health related Quality of Life and its socio-demographic determinants among Iranian elderly people: A population based cross-sectional study. Journal of Caring Sciences, 6(1), pp. 39-47. [DOI:10.15171/jcs.2017.005]

Hongthong, D. \& Somrongthong, R., 2015. Factors influencing the Quality of Life (Qol) among Thai older people in a rural area of Thailand. Iranian Journal of Public Health, 44(4), pp. 47985. [PMID] [PMCID]

Jadidi, A., et al., 2011. [The relationship between Spiritual WellBeing and Quality of Life among elderly people residing in Kahrizak senior house (Persian)]. Iran Journal of Nursing, 24(72), pp. 48-56.

Jahromi, M. K., Ramezanli, S. \& Taheri, L., 2015. Effectiveness of diabetes self-management education on Quality of Life in diabetic elderly females. Global Journal of Health Science, 7(1), pp. 10-5. [doi:10.5539/gjhs.v7n1p10] [PMID] [PMCID]

Jokinen, N. S., 2014. Quality of Life and older aged adults. International Public Health Journal, 6(4), p. 371.

Khaje-Bishak, Y., et al., 2014. Assessing the Quality of Life in elderly people and related factors in Tabriz, Iran. Journal of Caring Sciences, 3(4), p. 257. [PMID] [PMCID]

Kim, C. J., et al., 2015. Cognitive aging function and lifestyle behaviors among older adults with chronic diseases. Paper presented at $10^{\text {th }}$ International Nursing Conference, Manila, Philippines, 1 October 2015.

Kim, S. S., Kim-Godwin, Y. S. \& Koenig, H. G., 2016. Family spirituality and family health among Korean-American elderly couples. Journal of Religion and Health, 55(2), pp. 729-46. [DOI:10.1007/s10943-015-0107-5] [PMID]

Kiosses, D. N. \& Alexopoulos, G. S., 2014. Problem-solving therapy in the elderly. Current Treatment Options in Psychiatry, 1(1), pp. 15-26. [DOI:10.1007/s40501-013-0003-0] [PMID] [PMCID]

Kumar, G. \& Majumdar, A., 2014. Quality of Life (QOL) and its associated factors using WHOQOL-BREF among elderly in urban Puducherry, India. Journal of Clinical and Diagnostic Research, 8(1), pp. 54-7.

Lewis, S., et al., 2014. Spiritual well-being and its influence on fatigue in patients undergoing active cancer directed treatment: A correlational study. Journal of Cancer Research and Therapeutics, 10(3), pp. 676-80. [PMID]

Liang, Y. \& Lu, P., 2014. Medical insurance policy organized by Chinese government and the health inequity of the elderly: longitudinal comparison based on effect of new cooperative medical scheme on health of rural elderly in 22 provinces and cities. International Journal for Equity in Health, 13, p. 37. [DOI:10.1186/1475-9276-13-37]

López-Soto, P. J., 2015. 24-hour pattern of falls in hospitalized and long-term care institutionalized elderly persons: A systematic review of the published literature. Chronobiology international, 32(4), pp. 548-56. [DOI:10.3109/07420528.2014.987295]

Mangen, M. J., et al., 2017. Quality of Life in community-dwelling Dutch elderly measured by EQ-5D-3L. Health and Quality of Life Outcomes, 15, p. 3. [DOI:10.1186/s12955-016-0577-5] [PMID] [PMCID]
Mazloomy Mahmoodabad, S., et al., 2014. Education based on precede-proceed on Quality of Life in elderly. Global Journal of Health Science, 6(6), pp. 178-84. [DOI:10.5539/gihs.v6n6p178] [PMID] [PMCID]

Mehri Nejad, S. A., Ramezan Saatchi, L. \& Paydar, S., 2017. [Death anxiety and its relationship with social support and adherence to religion in the elderly (Persian)]. Iranian Journal of Ageing, 11(4), pp. 494-503. [DOI:10.21859/sija-1104494]

Miranda, L. C. V., Soares, S. M. \& Silva, P. A. B., 2016. Quality of Life and associated factors in elderly people at a Reference Center. Ciencia \& Saude Coletiva, 21(11), pp. 3533-44. [DOI:10.1590/1413-812320152111.21352015] [PMID]

Nasiry, Z. G. D., Bagheri, N. M. \& Malekzadeh, S. M., 2016. Relationship between Spiritual Well-Being and Quality of Life in multiple sclerosis patients. Journal of Nursing and Midwifery Sciences, 3(2), pp. 25-31.

Nazemi, L., et al., 2015. Malnutrition, prevalence and relation to some risk factors among elderly residents of nursing homes in Tehran, Iran. Iranian Journal of Public Health, 44(2), pp. 218-27. [PMID] [PMCID]

Nikkhah, M., et al., 2017. Psychometric properties of the Persian version of the Older People's Quality of Life Questionnaire (OPQOL-35). Health and Quality of Life Outcomes, 16(1), p. 174. [DOI:10.1186/s12955-018-1002-z] [PMID] [PMCID]

Poor, H. J., Borji, M., Borji, M. \& Moslemi, A., 2016. The relationship between Spiritual Well-Being and Quality of Life and optimism on the staff of Arak University of Medical Science. Health, Spirituality and Medical Ethnic, 3(2), pp. 8-15.

Rashedi, V., et al., 2016. Prevalence of disability in Iranian older adults in Tehran, Iran: A population-based study. Journal of Health and Social Sciences, 11(Suppl.1), pp. 251-62.

Ryff, C. D. \& Singer, B. H., 2008. Know thyself and become what you are: A eudaimonic approach to psychological well-being. Journal of Happiness Studies, 9(1), pp. 13-39. [DOI:10.1007/ s10902-006-9019-0]

Seraji, M., Shojaezade, D. \& Rakhshani, F., 2016. The relationship between Spiritual Well-Being and Quality of Life among the elderly people residing in Zahedan City (South-East of Iran). Elderly Health Journal, 2(2), pp. 84-8.

Shi, X., et al., 2017. Marital status and survival of patients with oral cavity squamous cell carcinoma: A population-based study. Oncotarget, 8(17), pp. 28526-43. [DOI:10.18632/oncotarget.16095]

Soliman, H. H., et al., 2015. Families' satisfaction with public housing in Saudi Arabia and its effect on the quality of their lives. Journal of Social Service Research, 41(1), pp. 385-97. [DOI:1 0.1080/01488376.2014.994798]

Steptoe, A., Deaton, A. \& Stone, A. A., 2015. Subjective wellbeing, health, and ageing. The Lancet, 385(9968), pp. 640-8. [DOI:10.1016/S0140-6736(13)61489-0]

Tkatch, R., et al., 2016. Population health management for older adults: Review of interventions for promoting successful aging across the health continuum. Gerontology and Geriatric Medicine, 2, p. 2333721416667877. [DOI:10.1177/2333721416667877] [PMID] [PMCID]

Van Nguyen, T., et al., 2017. Difference in Quality of Life and associated factors among the elderly in rural Vietnam. Journal 
of Preventive Medicine and Hygiene, 58(1), pp. E63-71. [PMID] [PMCID]

Velasco-Gonzalez, L. \& Rioux, L., 2014. The Spiritual Well-Being of elderly people: A study of a French sample. Journal of Religion and Health, 53(4), pp. 1123-37. [DOI:10.1007/s10943-0139710-5] [PMID]

Walker, S. J., et al., 2017. The relationships between Spiritual Well-Being, Quality of Life, and psychological factors before radiotherapy for prostate cancer. Journal of Religion and Health, 56(5), pp. 1846-55. [DOI:10.1007/s10943-016-0352-2] [PMID]

Wang, C. W., Chow, A. Y. \& Chan, C. L., 2017a. The effects of life review interventions on Spiritual Well-Being, psychological distress, and Quality of Life in patients with terminal or advanced cancer: A systematic review and meta-analysis of randomized controlled trials. Palliative Medicine, 31(10), pp. 883-94. [DOI:10.1177/0269216317705101]

Wang, F. L., et al., 2017b. Influence of marital status on the Quality of Life of Chinese adult patients with epilepsy. Chinese Medical Journal, 130(1), pp. 83-7. [DOI:10.4103/0366-6999.196572] [PMID] [PMCID]

Yin, S. S., et al., 2017. Quality of Life (QOL) and Its associated factors among rungus elderly population in the rural areas of $\mathrm{Ku}$ dat, Sabah. Borneo Journal of Medical Sciences, 11(1), pp. 42-55.

Zeinalhajlu, A. A., Amini, A. \& Tabrizi, J. S., 2015. [Consequences of population aging in Iran with emphasis on its increasing challenges on the health system (Literature review) (Persian)]. Depiction of Health, 6(1), PP. 54-64.

Zhou, J. \& Hearst, N., 2016. Health-related Quality of Life of among elders in rural China: The effect of widowhood. Quality of Life Research, 25(12), pp. 3087-95. [DOI:10.1007/s11136016-1338-y] [PMID] [PMCID]

Zimmer, Z., et al., 2016. Spirituality, religiosity, aging and health in global perspective: A review. SSM-Population Health, 2, pp. 373-81. [DOI: 10.1016/j.ssmph.2016.04.009] [PMID] [PMCID] 
This Page Intentionally Left Blank 